\title{
Three-dimensional Transesophageal Echocardiography of P2 Chordae Tendinae Rupture
}

\author{
Sait Demirkol ${ }^{1}$, Ibrahim Halil Kurt ${ }^{2}$, Oben Baysan ${ }^{1}$ and Turgay Celik ${ }^{1}$
}

Key words: Three-Dimensional Transesophageal Echocardiography, Chordae Tendinae Rupture

(Intern Med 50: 2683-2684, 2011)

(DOI: 10.2169/internalmedicine.50.6254)
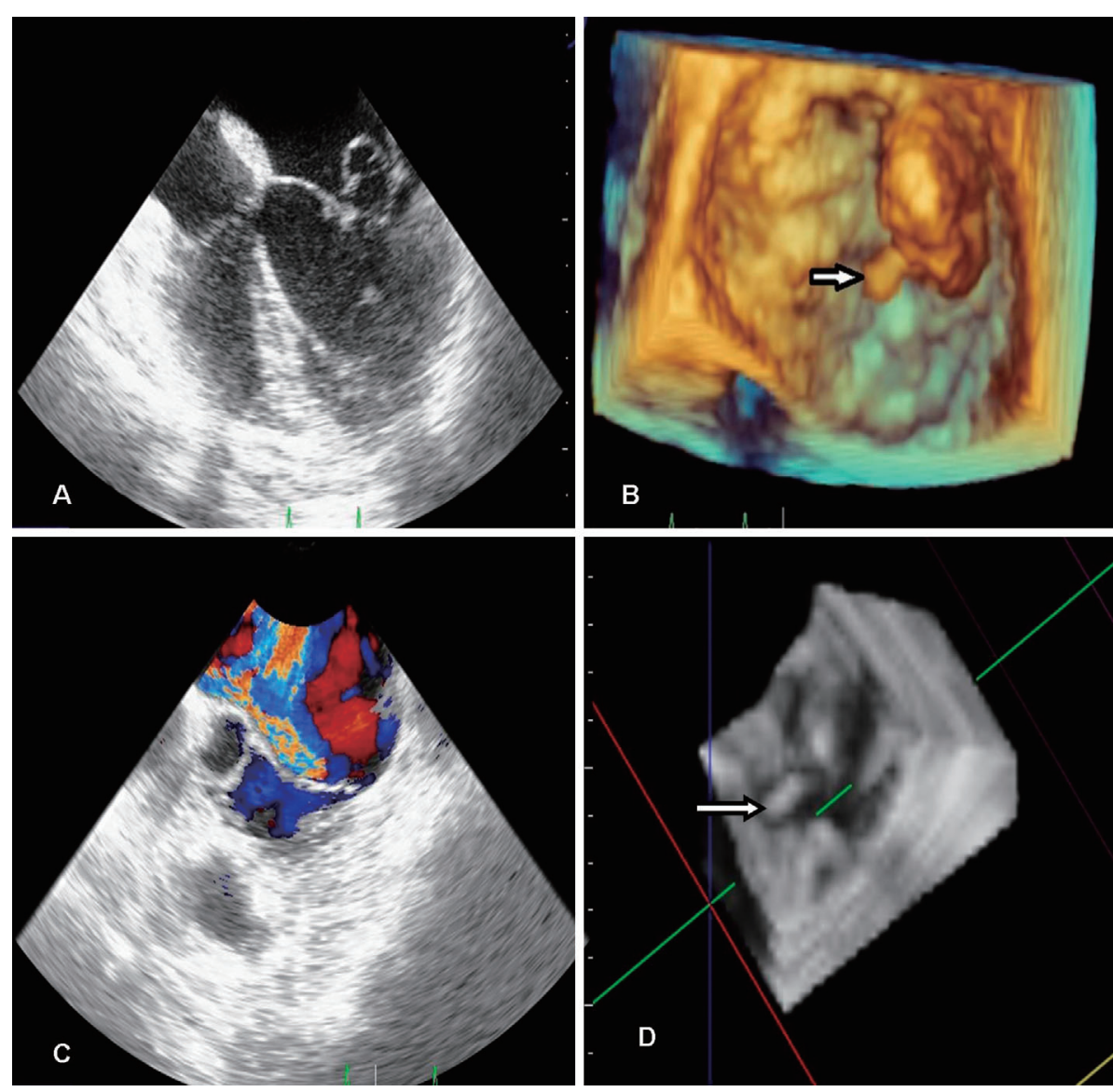

Picture

A 54-year-old man was admitted to our department because of shortness of breath and palpitation. He had hypertension and diabetes mellitus. Transesophageal echocardiography revealed severe mitral regurgitation and prolapsing segment of the posterior mitral valve (Picture A, C). Three-dimensional transesophageal echocardiography (3D
TEE) was performed for the assessment of the individual mitral valve segments. 3D TEE findings facilitate the diagnosis of prolapse and chordae rupture of P2 scallop (Picture B, D).

Chordae tendinae rupture (CTR) is one of the major causes of mitral regurgitation. However bacterial endocardi-

${ }^{1}$ Department of Cardiology, School of Medicine, Gulhane Military Medical Academy, Turkey and ${ }^{2}$ Department of Cardiology, Numune Research Hospital, Turkey

Received for publication July 27, 2011; Accepted for publication July 29, 2011

Correspondence to Dr. Sait Demirkol, saitdemirkol@yahoo.com 
tis and rheumatic heart disease are also common causes of CTR, and the etiology of CTR is still obscure in many patients. Detailed examination of the leaflet is necessary to verify which scallop is actually prolapsing. A definite diagnosis can be made with 3D TEE imaging. The advent of 3D echocardiography has given physicians the ability to visualize the mitral anatomy in any desired plane.

The authors state that they have no Conflict of Interest (COI).

(C) 2011 The Japanese Society of Internal Medicine http://www.naika.or.jp/imindex.html 